\title{
A casa de Saul e suas divindades
}

\author{
The house of Saul and its deities
}

Silas Klein Cardoso *

\begin{abstract}
* Doutor em Ciências da Religião pela Universidade metodista de São Paulo, Pósdoutor em Antigo Testamento e Mundo Bíblico pela Universidade de Berna e em História da Religião/Religiões Comparadas pela Universidade de Zurique. Pesquisador no Departamento de Estudos da Religião da Universidade de Zurique, Suíça, no contexto do projeto Stamp Seals from the Southern Levant (Sinergia-SNSF).

Bolsista de pós-doutorado pelo programa Grande Prêmio Capes de Tese. silasklein@gmail.com
\end{abstract}

Recebido em: 10/10/2021

Aprovado em: 20/10/2021

Licença Creative Commons
CC BY 4.0 CC BY 4.0

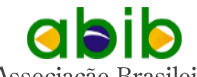

Associação Brasileira de Pesquisa Bíblica

\section{Resumo}

A região e o período geralmente associados ao rei Saul, i.e., o platô de Benjamim no Período do Ferro I-IIA inicial (c. 1125-875 AEC), tem sido alvo de intensos debates nos últimos quinze anos. Enquanto estudos arqueológicos e exegéticos europeus, norte-americanos e israelenses têm permanecido restritos à discussão sóciodemográfica e política da região, as crenças e práticas religiosas dos habitantes têm sido negligenciadas. Em contraposição a essa vertente, o presente estudo examina as fontes arqueológicas, epigráficas e bíblicas do período para identificar as divindades supostamente cultuadas pela casa de Saul. Tal tarefa, descrita como impossível por proeminentes estudiosos nos últimos anos, faz-se possível pelo quadro conceitual intitulado "redes mágico-míticas", que observa a religião através de uma perspectiva comunicológica, junto à integração de dados da cultura visual, geralmente esquecida. Assim, para a identificação das divindades cultuadas na região, os vestígios artísticos são analisados material e iconograficamente e, depois, são comparados aos nomes de indivíduos (antropônimos) e locais (topônimos) conhecidos para ver os possíveis nomes das deidades. Dessa forma, ao utilizar a organização social e os dados de múltiplas fontes, o artigo propõe dois níveis de deidades que provavelmente fizeram parte da experiência religiosa dos habitantes, tal qual a possível identificação dessas deidades.

Palavras-chave: Platô de Benjamin; divindades; Saul; 1Samuel; iconografia; onomástica.

\begin{abstract}
The region and period generally associated with King Saul, i.e., the plateau of Benjamin in the Early Iron I-IIA Period (c. 1125-875 B.C.E.), has been the subject of intense debate over the past fifteen years. While European, North American, and Israeli archaeological and exegetical studies have remained restricted to socio-demographic and political discussion of the region, the religious beliefs and practices of the region's inhabitants have been neglected. In contrast to this strand, the present study examines the archaeological, epigraphic, and biblical sources of the period to identify the deities supposedly worshipped by the house of Saul. Such a task, described as impossible by prominent scholars in recent years, is made possible by the conceptual framework entitled "magicalmythic networks," which observes religion through a
\end{abstract}


communicological perspective and by integrating data from visual culture neglected by these scholars. In order to identify the deities worshiped in the region, the artistic traces are analyzed materially and iconographically, and then compared to the names of known individuals (anthroponyms) and places (toponyms) to see the possible designations of the deities. Thus, by using the social organization and data from multiple sources, the article proposes two levels of deities that were likely part of the inhabitants' religious experience, as well as their possible identification.

Keywords: Benjamin's Plateau; deities; Saul; 1Samuel; iconography; onomastics.

\section{Introdução ${ }^{1}$}

A história bíblica de Saul é irresistível. O conto de um líder divinamente escolhido que traiu sua deidade e seu povo, apenas para acabar destronado por um mero pastor (que matava gigantes!), alimentou a imaginação de muitos no decorrer da história (EHRLICH, 2016) ${ }^{2}$. Contudo, assim como a maioria dos textos bíblicos que retratam eventos, as bases históricas da estória não são facilmente detectadas. Apesar de não haver muitas razões para duvidar da existência de um Saul (DIETRICH, 2007, p. 166), os fatos estão enterrados sob muitas camadas de redações e ideologias que podem apenas ser descobertas em leituras contra o grão (KNAUF; GUILLAUME, 2016, p. 62-71). Ao mesmo tempo, o papel do rei na formação da chefatura que se tornou (o segundo? Terceiro?) Israel (FINKELSTEIN, 2019; KNAUF, 2016) e a cronologia de seu reino, o fizeram um atraente objeto de pesquisa na última década ${ }^{3}$. Isso resultou em reconstruções a partir da arqueologia (p. ex., FAUST, 2006; FINKELSTEIN, 2015; SERGI, 2017) e exegese bíblica (p. ex., FLEMING, 2012; GIFFONE, 2018; MILLSTEIN, 2016).

Enquanto as reconstruções históricas sobre Saul divergem em muitos aspectos, a localização no tempo e no espaço é uma convergência. Segundo os textos bíblicos, a "casa/dinastia" de Saul (heb. bêt $̌ s \bar{a}$ ' $u l)$ reinou a partir da região entre os centros meridional e setentrional da região montanhosa central (p. ex., 2Sm 2, 9). Tal área ficou conhecida nos textos bíblicos por sua ligação ao lendário patriarca Benjamim (heb. binyāmîn, Js 18,11-18) e prosperou todas as vezes que o poder de seus vizinhos do sul (Jerusalém, Al-Quds) e norte (Siquém, Tel Balâțah) desvaneceu (Js 2-9; 1Sm 8-12; 2Rs 25, 22-23; Jr 40, 6; Ed 4). A ligação entre a casa de Saul e a região é tão marcante que

1 Este artigo amplia e revisa pesquisas publicadas em língua inglesa. A pesquisa que originou o estudo foi realizada sob auspícios da CAPES (PDSE: 88881.190593/2018-01) e no contexto do Departamento de Estudos da Religião da Universidade de Zurique entre 2018/19. Sua tradução e atualização foi realizada também na Universidade de Zurique, agora sob o contexto do Stamp Seals from the Southern Levant (Sinergia, SNSF), onde continuo minha pesquisa sobre a glíptica benjaminita e a perspectiva da Exegese Iconográfica. Agradeço aos colegas de departamento e de SSSL pelo ambiente instigante de pesquisa e aos dois pareceristas designados pelas pontuais, mas valiosas sugestões de aprimoramento. Erros e opiniões são de minha responsabilidade.

2 Devido aos limites editoriais, mantive referências bibliográficas ao mínimo. As obras mencionadas ou são de caráter seminal ou possuem bibliografia atualizada. Todas as traduções de língua estrangeiras são minhas.

3 Para outras pesquisas recentes, veja Krause, Sergi e Weingart (2020). 
o próprio Saul é chamado "benjaminita" (heb. ben-yěmîn̂̂, $1 \mathrm{Sm} 9,21$, cf. S1 7, 1; 1Cr $27,12)$. É notável que esse platô, chamado aqui de "platô de Benjamim" também tenha visto acontecimentos transformadores na época geralmente associada a Saul, os séculos 12-10 AEC. Levantamentos arqueológicos levados a cabo entre o final dos anos 1980 e o início dos anos 1990 notaram uma concentração de assentamentos de médio e grande porte nessa mesma região (FINKELSTEIN; MAGEN, 1993, p. 13-79, 447452). De igual modo, a dinâmica populacional narrada nos textos bíblicos também é vista arqueologicamente (MILLER II, 2005, p. 20, 29-30, 81-82; LEHMANN, 2004, p. 158-164).

Mapa 1 - Platô de Benjamim (amarelo), Judá (azul) e Efraim (vermelho). Os círculos são apenas reforços ilustrativos, não representam os limites exatos dessas unidades políticas

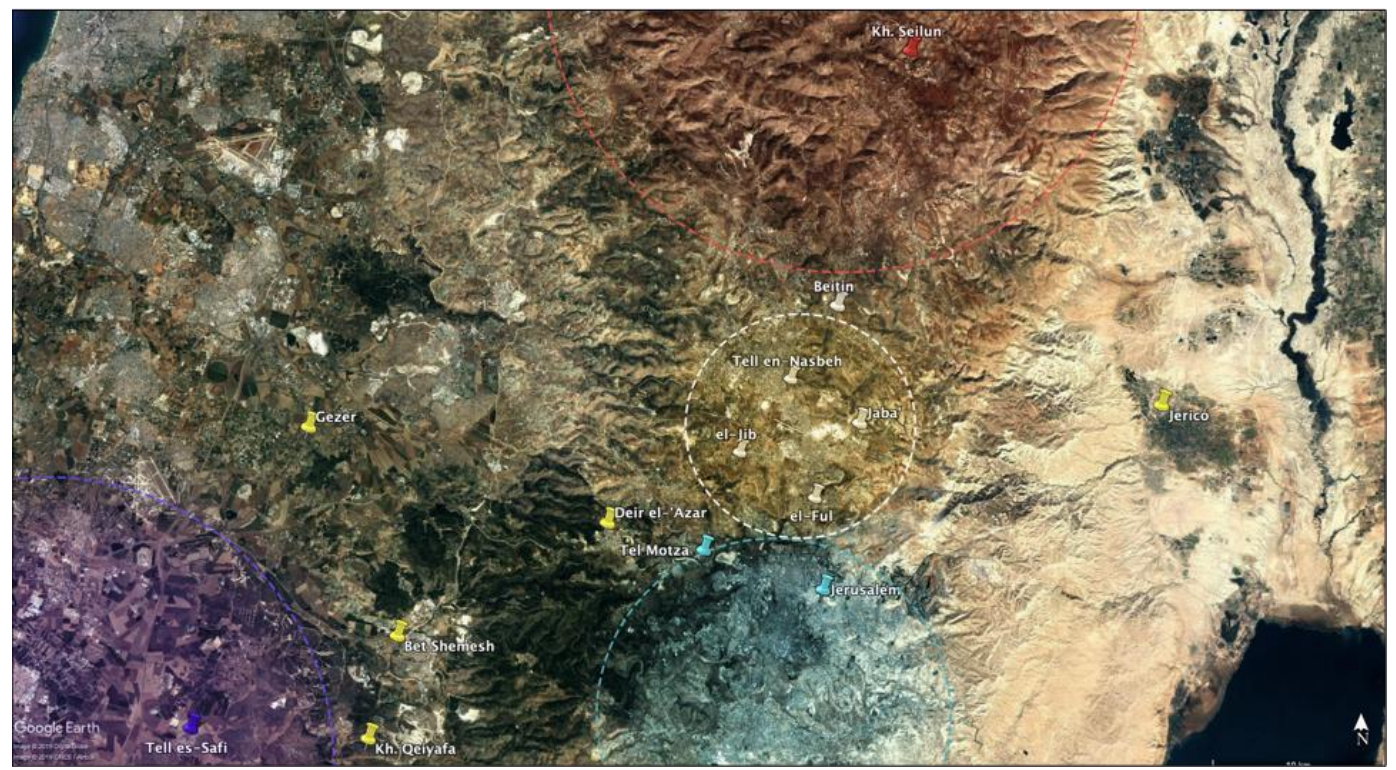

Fonte: Adaptado do Google Earth, 2021.

Enquanto a rara convergência entre narrativa bíblica e cultura material aumentou o número de estudos sobre a região e o período nos últimos anos, a história religiosa de Benjamim foi, até pouco tempo, quase completamente negligenciada (mas veja LANGSTON, 1998; TOORN, 1996) ${ }^{4}$. Esse fato é curioso, haja vista o retrato bíblico

4 A falta de pesquisas não se dá por acaso. Em primeiro lugar, há uma predisposição à negligência de pequenas unidades do "Antigo Israel" em prol de reconstruções generalizantes que assumam uma "distinção israelita" e o problemático conceito de "antigo Israel/Israel bíblico" (DAVIES, 2015). A segunda tendência é aquela que prioriza padrões recorrentes e gerais em lugar de práticas localizadas. Mesmo com esforços pontuais para destacar padrões locais ou dimensões pessoais e domésticas da religiosidade antiga, o maior número de reconstruções a lidar com a História da Religião da antiga Palestina no primeiro milênio AEC favoreceu as conexões e não peculiaridades regionais. As diferenciações feitas, geralmente, se constroem sobre problemáticas distinções étnico-políticas (p. ex., "filisteu", "edomita", "israelita" etc.) e não em práticas localizadas. Esse procedimento implica não apenas 
ser deveras atraente: segundo o texto bíblico, Benjamim possui ao menos cinco templos no período (BLENKINSOPP, 1972, p. 68-69), algo tão significante quanto atípico. Isso justifica o esforço para apresentar um cenário compreensivo e escrito por múltiplas fontes na região, que discute sua história religiosa (KLEIN CARDOSO, 2019), a dissonância entre locais de cultos no texto bíblico e registro arqueológico (KLEIN CARDOSO, 2020b), além de estudos de caso particulares (KLEIN CARDOSO, 2020a). Este artigo acrescenta novos dados ao discutir a casa de Saul e suas divindades. Ao contrário do que defendeu um proeminente arqueólogo recentemente (FINKELSTEIN, 2015, p. 71, n. 6), penso ser, sim, possível identificar as divindades cultuadas na região. Assim, este artigo observa as deidades presentes na região do platô de Benjamim no período do Ferro I-IIA inicial". O que chamo "platô de Benjamim" se limita pelo Vale de Rift à leste, pela descendente que vai em direção à Sefelá à oeste, pelos limites de Beitin $\left(B \operatorname{ctel}^{6}\right)$ e et-Tell (Ai?) à norte e, à sul, pela depressão que antecede Jerusalém. Os sítios que divisam a região são: Jeba (Geba?; 9,6 km NE-Jerusalém) ao leste; Tell en-Nasḅeh (Mispa; 12 km NO-Jerusalém) ao norte; el-Jîb (Gibeão; 9,6 km NO-Jerusalém) ao oeste; Tell el-Fûl (Gibeá?; 4,8 km N-Jerusalém) (veja Mapa 1).

\section{Sobre método}

\subsection{Acessando religião no platô de Benjamim: redes mágico- míticas}

A utilidade de um conceito de "religião" ou, mesmo, a existência da categoria na Antiguidade é um tópico bastante discutido hoje (p. ex., ROUBEKAS, 2019). Esse não é o local para tratar da questão, haja vista outros estudos terem lidado com o problema de religião/ões israelitas antigas (p. ex., KLEIN CARDOSO 2019; 2020a; MANDELL; SMOAK, 2019). Devo mencionar, contudo, que esse artigo parte da ideia de que a realidade social, esta que abriga "religião", é construída e se desenvolve via processos comunicativos (veja KNOBLAUCH, 2020). Devido às particularidades dos Estudos Bíblicos e da História da Religião, disciplinas fortemente logocêntricas, é importante reconhecer que tais processos não devem ser reduzidos a uma instância midiática isolada como, p. ex., à mídia verbal escrita. É errôneo pensar, como certas abordagens fazem, que textos literários, como os bíblicos, sejam representações ideais da realidade.

problemas de ordem metodológica, mas evidencia tentativas de polarizar evidências em prol de agendas contemporâneas dos pesquisadores envolvidos.

5 É metodologicamente apropriado utilizar a cronologia relativa, haja vista esta estar ligada a classificações tipológicas e, também, haver dessincronia entre períodos relativos de diferentes regiões, algo que mascara os resultados. Para fins de orientação, utilizo nesse estudo as seguintes datas absolutas aproximadas: Ferro IA, c. 1125/1100-1050 AEC; Ferro IB, c. 1050-1025; Ferro IC, c. 1025-950/925 AEC; Ferro IIA, c. 950/925-925/875 AEC; Ferro IIB, c. 800/775-725/700; Ferro IIC, c. 725/700-575/550; Persa 575/550-300/250.

6 Enquanto prefiro tratar os sítios arqueológicos pelos nomes contemporâneos, assinalo entre parênteses as identificações com sítios bíblicos. Enquanto alguns são tomados por certo pela toponímia (p. ex., Beitin/Betel), evidências epigráficas (p. ex., Tell el-Jîb/Gibeão) ou histórico-geográficas (p. ex., Tell en-Nasḅeh/Mispa; et-Tell/Ai), outros são incertos e, por esse motivo, deixo uma interrogação em suas prováveis identificações. 
Além de epistemologicamente problemático, reconhecer a questão é fundamental para a análise de objetos de pesquisa sem fontes textuais. Esse é o caso do platô de Benjamim no Período do Ferro I-IIA, que não rendeu vestígios textuais, com a exceção de três letras em uma alça de jarra de datação duvidosa (LEDERMAN, 1999, p. 139-142; SASS; FINKELSTEIN, 2016). Ademais, leitores/as devem ter em mente que religião não ocorre apenas de forma abstrata, como ideias no papel, mas materialmente (p. ex., MEYER, 2020).

Além da materialidade e mídia, as estruturas de comunicação também têm seu papel na construção de religião. O conceito de "redes mágico míticas" considera tais estruturas presentes no platô de Benjamim no Ferro I-IIA. A região estava organizada como uma chefatura complexa, i.e., uma sociedade pré-estatal com tributação móvel, ciclos entre poderes, e sacralização da linhagem dos chefes (MILLER II, 2005). A interação se dava a partir de laços familiares dentre um raio de 10 km (LEHMANN, 2004; LEHMANN, 2012), um aspecto também sugerido pelo planejamento de cidade (FINKELSTEIN, 2015; veja KLEIN CARDOSO, 2019, p. 179-181) e espaços funerários, estes que também sugerem uma aristocracia rural (LEHMANN; VARONER, 2018, p. 261, 263; KLEIN CARDOSO, 2019, p. 184-186). Enquanto esses laços regionais tornam aprazível a utilização de uma perspectiva de "redes[-sociais]", a ausência de aparato burocrático dá lugar para o conceito "mágico-mítico". Embora tenha uma ressonância religiosa, o conceito "mágico-mítico" é comunicológico. Vilém Flusser (2014, p. 52-57) propôs que as estruturas comunicacionais de sociedades pré-históricas (i.e., sociedades sem escrita) apresentavam duas características: (1) elas eram míticas, i.e., principalmente orais, nas quais o emissor do processo comunicativo se posicionava no centro, em posição adequada para responder diretamente aos emissores e formar diálogo; e (2) eram mágicas, i.e., a memória estava intersubjetivamente transposta em objetos materiais, estes que preservavam fisicamente a memória de gestos e uso.

Em outras palavras, por "redes mágico-míticas" me refiro a sistemas simbólicoreligiosos expressos em comunicação oral (p. ex., mitos, estórias, lendas) e materializados em objetos (p. ex., cerâmica, selos, talismãs, estatuetas). A estrutura comunicativa é, portanto, circular, centrada em vilas graduadas, cujas particularidades criam e são criadas a partir do contato com o ambiente e dinâmicas sociais. Duas observações, aqui, são requeridas. Em primeiro lugar, "ser expresso em comunicação oral/artefatos" significa que essas práticas não estão constritas a estruturas cúlticas, mas atingem todas as esferas da vida comum. De igual modo, a assimetria das redes não leva ao caos. As condições produtivas geram sistemas de disposições similares, ou seja, como orquestrações sem um líder de orquestra, pelo princípio de ação comum (BOURDIEU, 2002, p. 169).

\subsection{As fontes para a história da religião do platô de Benjamim}

A compreensão crítica das fontes precisa estar no centro do esforço histórico, haja vista que "a história não está nas fontes, mas precisa das fontes para ser escrita" (UEHLINGER, 2001, p. 31). Christoph Uehlinger (2001, p. 35), nesse sentido, classificou as fontes por sua relação relativa aos eventos históricos. Em sua classificação, 
fontes primárias $^{7}$ seriam aquelas datadas com relativa segurança por critérios arqueológicos (i.e., estratigrafia, tipologia) ou criadas dentre uma geração após os eventos retratados. $\mathrm{O}$ autor alerta, contudo, ao fato de que uma fonte ser primária não significa que ela não pode mentir. Nisso, a taxonomia de fontes de José D'Assunção Barros (2019) se torna atrativa. O historiador classifica fontes de acordo com sua: (1) posição, que pode ser (1a) temporal, $(1 \mathrm{~b})$ espacial, $(1 \mathrm{c})$ ideológica ou $(1 \mathrm{~d})$ relacionada à questão de pesquisa; (2) qualidade, que pode ser dividida entre (2a) fontes de conteúdo e (2b) fontes materiais; (3) intencionalidade; e (4) serialização. As múltiplas possibilidades de categorização de fontes dentre um mesmo grupo de evidências históricas demonstram a importância de se ter uma questão de pesquisa bem desenhada.

Sob essa perspectiva, é importante notar que as narrativas bíblicas sobre Benjamim não podem ser consideradas fontes primárias para a questão das divindades. Com relação à sua posição, os mais antigos manuscritos de Samuel são do terceiro ou segundo século AEC, quando analisados sob critérios paleográficos e crítico-textuais (LANGE, 2016). Isso significa que, caso correta, eles distariam setecentos anos dos eventos retratados e quatrocentos anos após os testemunhos textuais mais antigos (veja sobre isso DIETRICH, 2007, p. 272-284; MILSTEIN, 2016, p. 175-206). Com relação à intencionalidade, o gênero literário dos textos é principalmente compósito e de caráter lendário. O enredo, em si, manifesta-se sob acentos ideológicos e políticos (KLEIN CARDOSO, 2019, p. 317-353).

Em contraposição, nove sítios arqueológicos escavados podem ser assinalados ao período e região: Beitin (Betel), Tell el-Jib (Gibeão), et-Tell (Ai?), Kh. Abū-Musarrah, Kh. ed-Dawwara, Kh. Nisieh, Kh. Raddana, Tell el-Fûl (Gibeá? Faraton?), Tell enNasḅeh (Mispa $)^{8}$. Um acesso produtivo à questão das divindades se dá pela onomástica (i.e., o estudo dos nomes) e a iconografia (i.e., estudo histórico de vestígios visuais). Enquanto a antroponímia tem sido utilizada extensivamente para nomes de divindades (p. ex., NOTH, 1928; ZADOK, 1988), seu uso juntamente a topônimos, estes que possuem estruturas de longa-duração (veja ELITZUR, 2004), tem demonstrado grandes possibilidades (p. ex., ZEVIT, 2001, p. 586-610). Contudo, a escassez de achados epigráficos anteriores ao nono século AEC tem gerado clamores de que seria impossível nomear as divindades das terras altas no final do Ferro I (FINKELSTEIN, 2015, p. 71, n. 6; mas veja ALBERTZ; SCHMITT, 2012, p. 254-386, 534-609; GOLUB, 2014). Nesse sentido, este estudo acrescenta análise da iconografia de selos anepigráficos ${ }^{9} \mathrm{da}$ região e período para, junto à análise dos antropônimos e topônimos do contexto, notar as estruturas do imaginário sobre as deusas e deuses da religião.

7 Para ele, secundárias seriam aqueles sem conhecimento direto dos eventos, terciárias aquelas sem acesso a fontes primárias e quaternárias aqueles que, sem fontes, produzem uma narrativa coerente, mas acrítica.

8 Para o histórico de assentamento, FINKELSTEIN, 2015, p. 57-84; MILLER II, 2005, p. 120-122; KLEIN CARDOSO, 2019, p. 177-196. Outros sítios da região foram escavados, mas não renderam camadas do Ferro I-IIA: El-'Eizariya, El-Qubeibeh, Kh. Hayian, Nebi Samwil, Kh. Shilha. Kh. Qeiyafa, não foi considerado por sua distância, enquanto o estágio das escavações em Moẓa e Deir el-'Azar (Kh-Jearim) não permitem incluí-las. Sobre Deir el-'Azar (Kh-Jearim), veja Finkelstein e Römer (2019).

9 O termo "anepigráfico" significa sem (gr. an) inscrição (gr. epigrăphē). Assim, selos anepigráficos, portanto, são aqueles que não trazem inscrições verbais, como, p. ex., nomes e funções dos proprietários. 


\section{As evidências disponíveis}

\subsection{Cultura visual de Benjamim no Ferro I-IIA}

A cultura visual da região compreende 67 selos, uma estatueta completa e três outros portadores de imagens. Panoramicamente, é possível analisar os artefatos por sua iconografia, distribuição e tipologia. Considerando a iconografia, três constelações são encontradas, com símbolos ligados a: (1) fertilidade ( 29 selos $=43,2 \%)$; (2) proteção $(18=26,8 \%)$; (3) guerra/caça $(6=8,9 \%)$; (4) liderança/chefatura $(4=5,9 \%)$. Dez selos $(14,9 \%)$ são geométricos ou não-legíveis. A distribuição de motivos é assimétrica no platô e região ${ }^{10}$, o que pode ser resultado da característica fronteiriça do platô. Dada a preferência tipológica por escarabóides $(17=30,3 \%)$ e conóides $(14=25 \%)$ e materiais utilizados (enstatita $[12=24,4 \%]$, pedra $[10=20,4 \%]^{11}$, é possível argumentar para a produção local dos selos no Ferro IB/C. Escaravelhos (14=25\%) e o repertório limitado de temas egípcios sugere uma reinstalação de poder pontual, possivelmente entre os reinos de Siamun e Sheshonq I (MÜNGER, 2005; KOCH, 2018).

Pelos dados disponíveis, é possível notar cinco tipos de seres sobrenaturais que, em ordem de aparição, poderiam ser caracterizados como: (1) deusa-mãe; (2) deus do clima; (3) deusa guerreira; (4) deus guerreiro; (5) divindade do deserto.

\subsubsection{Deusa-mãe}

A deidade mais popular no registro é uma deusa que, provavelmente, estava ligada a ideias de cuidado materno e proteção dos cultuantes, assim como à prosperidade dos rebanhos e cultivo. Além do suporte cúltico de et-Tell com figuração de leoas nas bases (MARQUET-KRAUSE, 1949, p. 109, n. 1052, pl. lxiv; lxxiv), outros cinco grupos compõem o quadro maior.

O primeiro é representado por cultuantes ao redor de árvores (Fig. 1a-c). O motivo iconográfico é típico dos séculos 10 e 9 AEC, estando ligado aos cultos envolvendo árvores, além de simbolizar cuidado materno e proteção aos vivos e mortos (SCHROER, 2018, p. 326). A árvore (tamareira?) pode surgir em vaso (Fig. 1b?), enquanto a forma dos cultuantes pode sugerir dança (SCHACHTER, 2010). O tema permanece até períodos posteriores, como pode ser visto na adaptação tardia que traz homens ${ }^{12}$ em vestes neo-assírias (Fig. 1c). O segundo grupo tem caprinos com um ramo (Fig. 1d, e?). O animal (caprino, gazela) e ramo (KEEL, 1995, p. 422) estão ligados ao imaginário da deusa, relembrando seu auxílio em matérias de fertilidade. $\mathrm{O}$ abutre aparece desde o Período do Bronze com leões, ramos, e mulheres, estando ligado à deusa-

10 Motivos agrícolas: Sefelá (Lachish, Beth-Shemesh, Gezer, Ecrom), Benjamim/Judá (Beitin, Nasḅeh, el-Jib, Jerusalem), região de Samaria (el-Far'ah North, Samaria, Rehov, Megiddo). Motivos pecuários: Sefelá (Gezer, Beth-Shemesh), Benjamim (Nasḅeh, Beitin). O tema "senhor/a dos animais" surge na Sefelá e Benjamim.

11 Motivos autóctones da região sugerem o mesmo como, p. ex., (1) caprinos sob o escorpião, (2) humanos ao redor de uma árvore, (2) senhor/a dos animais, (4) deidades guerreiras masculinas e femininas.

12 Enquanto as outras cenas não identificam gênero, a Fig. 1c apresenta os indivíduos com barba. 
árvore (SCHROER, 2008a, p. 150-151, 216-219, n. 368, 450, 453). Sua aparição junto ao escaravelho (Fig. 1f) aponta para Necbete e o reino dos mortos (SCHROER, 2008b).

Figura 1 - Selos e impressões com iconografia ligada ao imaginário de uma deusa-mãe

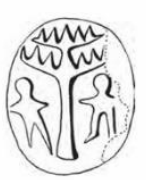

(a)

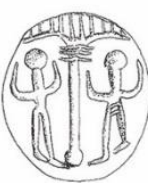

(b)

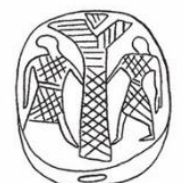

(c)

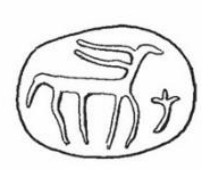

(d)

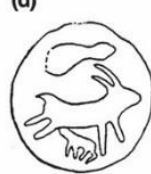

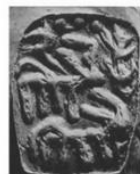

(e)

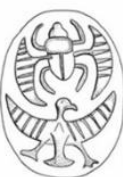

(f)

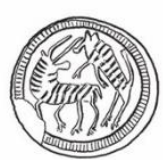

(g)

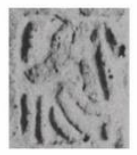

(h)

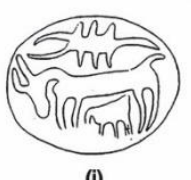

(j)

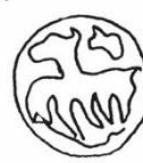

(k)

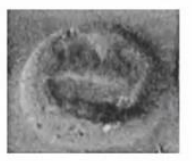

(m)

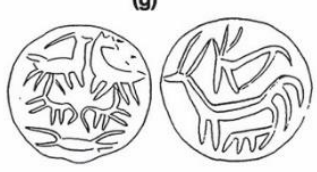

(o)

Fonte: (a) Beitin (KEEL, 2010a, p. 28, n. 18); (b) el-Jib (KEEL, 2013, p. 466, n. 3); (c) Nasbeh (McCOWN, 1947, pl. 54.47); (d) Nasḅeh (SCHROER, 2018, p. 566, n. 1581); (e) Beitin (KEEL, 2010a, p. 31, n. 22); (f) Nasbeh (McCOWN, 1947, pl. 55.75); (g) Nasbeh (SCHROER, 2008b); (h) Beitin (KEEL, 2010a, p. 22, n. 7); (i) Beitin (KEEL, 2010a, p. 24, n. 13); (j) el-Jib (KEEL, 2013, p. 472, n. 18); (k) Nasbeh (SHUVAL, 1990, p. 108, n. 84); (1) Nasḅeh (SHUVAL, 1990, p. 106, n. 78); (m) Nasḅeh (KEEL, 1985, p. 37, n. 14); (n) Nasbeh (McCOWN, 1947, pl. 54.29); (o) Nasḅeh (KEEL, 1985, p. 36, n. 10); (p) Nasḅeh (KEEL, 1985, p. 37, n. 15).

Dois outros motivos não estão exclusivamente ligados a deusas. O primeiro é o leão atacando um animal (Fig. 1g-h) que pode carregar nuances sexuais (KEEL, 1995, fig. 360) ou, após a conquista do Egito, representar a "vitória" do rei egípcio (KEEL; UEHLINGER, 1998, p. 120). Outro motivo ligado à fertilidade é o de animais [mamando] abaixo do escorpião (Fig. 1 i-o, e?). A aparição da constelação de escorpião no céu marca o início do inverno e era vista como um sinal de prosperidade e bem-estar dos rebanhos (STAUBLI, 2010).

\subsubsection{Deus do clima}

A cratera de Raddana (CALLAWAY; COOLEY 1971) e três selos sugerem a presença de um deus do clima na região. O primeiro selo a servir de evidência é o de uma figura humana sobre um touro (Fig. 2a). A iconografia do touro enfatiza o aspecto da fertilidade do deus do clima (ORNAN, 2001, p. 24-26) e, a partir do Ferro I, seus gestos ameaçadores retratam sua natureza guerreira (CORNELIUS, 1994, p. 262). A figura do leão sobre a montanha (Fig. 2b) é de difícil interpretação. Enquanto o leão e a figura humana aparentemente masculina parecem sugerir Baal, a falta de asas, típica do Ferro I, das vestes egípcias, e do misterioso objeto em suas mãos dificulta a interpretação (SCHROER, 2018, p. 344; mas veja KLEIN CARDOSO, 2021, p. 8-9, fig. 1d). A divindade entronizada com uma flor de lótus e um adorador (Fig. 2c) podem ser vistas como um deus do clima entronizado típico da transição entre o Período do Bronze e Ferro I (veja KEEL; UEHLINGER, 1998, p. 58-59, fig. 56). A interpretação é possível caso se entenda a "árvore" (KEEL; UEHLINGER, 1998, p. 154) como uma flor de lótus, uma interpretação que parece mais provável (KLEIN CARDOSO, 2021, p. 9-10, fig. 2a). 
Figura 2 - Selos $(a, c)$ e impressão de selo (b) com iconografia ligadas ao imaginário do deus do clima

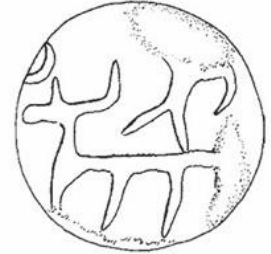

(a)

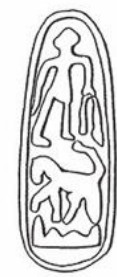

(b)

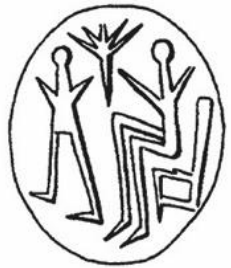

(c)

Fonte: (a) el-Jib (KEEL, 2013, p. 474, n. 20); (b) Nasbeheh (SHUVAL, 1990, p. 130, n. 35); (c) Nasḅeh (KEEL; UEHLINGER, 1998, n. 181).

\subsubsection{Deusa guerreira}

As figuras humanas com pose não-ameaçadora sobre cavalos sugerem uma deusa guerreira no imaginário da região. O retrato é evidente em dois escaravelhos com um adorador e uma figura humana sobre um cavalo, a primeira sentada (Fig. 3a) e a outra em pé (Fig. 3b). O perfil pode ser assinalado tanto para Astarte ou Anate (CORNELIUS, 2008, p. 44-45).

Figura 3 - Selos com iconografia ligada ao imaginário de uma deusa guerreira

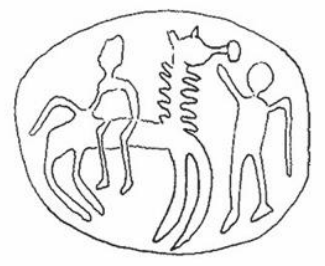

(a)

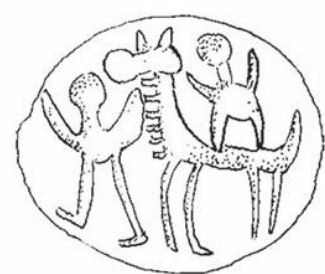

(b)

Fonte: (a) el-Jib 4 (KEEL, 2013, p. 466, n. 4); (b) el-Jib 8 (KEEL, 2013, p. 468, n. 8).

\subsubsection{Deus guerreiro}

As figuras antropomórficas sobre um animal com chifres em pose ameaçadora indicam a presença de um deus guerreiro. Este pode ser o caso da Fig. 4a e o gesto ameaçador (CORNELIUS, 1994, p. 25-57), enquanto a Fig. 4b é geralmente conectada a Resefe (CORNELIUS, 1994, p. 117-118; SCHROER, 2018, p. 342-343; KOCH 2018, p. 643). A deidade ctônica foi popular durante o terceiro e segundo milênio AEC e foi rebaixada para ser coadjuvante de chefes de panteão no primeiro milênio AEC (p. ex., Ba'al, Hadade, El, Shamash). Na Bíblia Hebraica, Resefe aparece primeiro como uma divindade que traz pragas, então como uma figura demônica que executa serviços para divindades principais e sobrevive em textos pós-exílicos em forma de pestilência (Dt 32, 24; S1 78, 48) (MÜNNICH, 2013). 
Figura 4 - Selos com iconografia ligada ao imaginário de um deus guerreiro

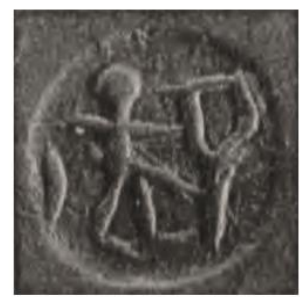

(a)
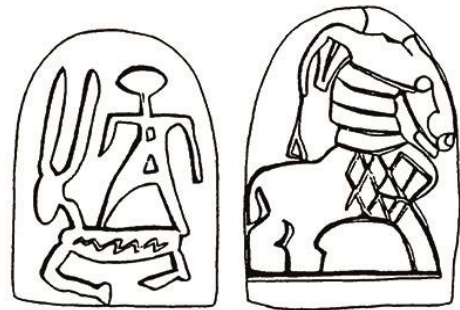

(b)

Fonte: (a) Nasbeh (McCOWN, 1947, pl. 54.30); (b) Nasbeh (SHUVAL, 1990, p. 143, n. 44).

\subsubsection{Deus desértico}

As três aparições de avestruzes sugerem um deus desértico. A primeira representação é de um avestruz com uma planta e uma marca (Fig. 5a), a segunda de uma figura humana em frente a um avestruz (Fig. 5b), e a terceira de uma figura humana entre dois avestruzes (Fig. 5c). O motivo de figuras humanas entre animais ameaçadores surge desde a metade do terceiro milênio AEC e, possivelmente, representa um herói/heroína enfrentando poderes do caos (KEEL, 1978, p. 86-125; SCHROER, 2018, p. 332). Os avestruzes dos dois primeiros selos podem ser interpretados em relação ao terceiro, que geralmente é associado a divindades do deserto (Jó 39, 13-16; KEEL; UEHLINGER, 1998, p. 385). O cenário desértico pode estar conectado a figurações do deus edomita Cos ou $y h w h$ (KNAUF 1999a, 1999b).

Figura 5 - Selos com iconografia ligada ao imaginário de um deus desértico

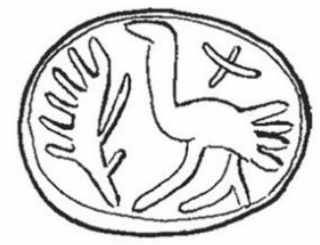

(a)

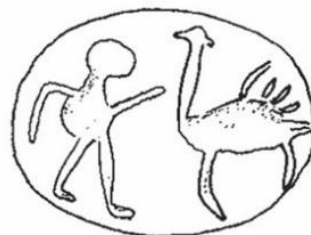

(b)

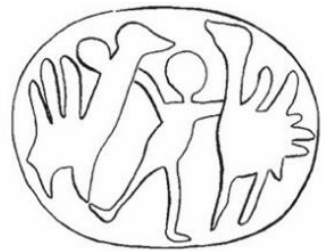

(c)

Fonte: (a) Beitin (KEEL, 2010a, p. 24, n. 12); (b) El-Jib (KEEL, 2013, p. 468, n. 5), (c) Nasbeh (KEEL, 1978, p. 104, n. 39).

\subsection{Cultura textual de Benjamim no Ferro I-IIA}

A partir da literatura bíblica, três topônimos estavam provavelmente ligados a santuários de divindades: (1) bêt 'èl (heb. casa/santuário de El, Js 18, 21); (2) ba 'al hāṣōwr (heb. palácio/santuário de Baal, 2Sm 13, 23); (3) bêt 'azmāwet (heb. casa/santuário do poderoso Mot, Ne 7,28). Embora Anate não apareça explicitamente ligada a um santuário, ‘̆nātōwt (heb. Anate é grande) pode denotar a adoção da deusa como patronesse dos habitantes da região. Ao se adicionar os nomes pessoais (antroponímia) para analisar os dados, é possível encontrar nos prefixos e sufixos dos nomes pessoais predicados ou epítetos de divindades cultuadas. A terminologia relacional (' $\bar{a} h$, heb. irmão; 'āb heb. pai; $r p$ ', heb. aquele/a que cura[?]; $m l k$, heb. rei) e šaḥar (heb. Shahar; 
alvorada) cabem nessa mesma categoria, ${ }^{13}$ enquanto seis nomes de divindades podem ser vistos nos antropônimos (Baal, El, Mot, Anate, Shemesh, $y h w h) .{ }^{14}$

Utilizando a relação entre nomes pessoais e de locais (Tabela 1) e pressupondo que a sobreposição entre os dois corpos indique maior acuidade histórica ${ }^{15}$, é possível nomear quatro divindades no registro: (1) ba 'al (heb. Baal; senhor); (2) 'él (heb. El; deus); (3) $m w t$ (heb. Mot; morte); (4) 'nt (Anate). Enquanto a ausência de $\check{s} m s ̌$ (heb. Shemesh; sol) é esperada, a ausência de $y h w h$ é surpreendente. Zevit (2001, p. 595) argumenta que tal ausência possa se dar por três motivos: (1) os locais de culto foram nomeados antes do javismo; (2) o javismo jamais foi disseminado no período/região; (3) yhwh não estava ligado a santuários locais, mas a santuários pessoais e comunitários (p. ex., heb. yhwh yêrā'e, Gn 22,14).

Tabela 1 - Antropônimos e topônimos bíblicos

\begin{tabular}{|c|c|c|c|c|c|c|c|c|c|c|c|c|}
\hline & ba'al & $r p^{\prime}$ & $m w t$ & 'ạh & $m r$ & ' $n t$ & $\check{s} m s ̌$ & 'èl & $y h w h$ & $' \bar{a} b$ & šaḥar & $m l k$ \\
\hline Antr.:Gn-Js & 1 & 1 & 2 & 2 & 0 & 1 & 0 & 3 & 2 & 1 & 1 & 0 \\
\hline Antr.: Jz- Sm & 1 & 1 & 1 & 4 & 0 & 1 & 1 & 6 & 10 & 3 & 2 & 0 \\
\hline Antr.: 1Sm - & 2 & 1 & $\mathbf{0}$ & 2 & 1 & $\mathbf{0}$ & 0 & 5 & 3 & 2 & 0 & 2 \\
\hline Topônimos & 2 & 0 & 1 & 0 & 0 & 1 & 0 & 2 & 0 & 0 & 0 & 0 \\
\hline Total & 6 & 3 & 4 & 8 & 4 & 3 & 4 & 16 & 15 & $\theta$ & 3 & $z$ \\
\hline
\end{tabular}

Fonte: o autor (2021).

Além dos dados bíblicos, o portal de Sheshonq I em Karnak apresenta um aglomerado de sítios em sua lista de nomes da região no grupo sudoeste. ${ }^{16}$ Os topônimos pertencem a três categorias (RAINEY, 1978), topografia, flora e produções humanas. Apesar de Kh. Jearim, Aijalon, e Zemaraim reforçaram aspectos naturais e conexões com a deusa mencionada acima, o único local com nome típico de santuário é Beth-

13 Ocorrências: (1) 'āh: 'ăhîrām (heb. meu irmão [divino é] exaltado, Nm 26, 38); 'ăhî̌šăhar (heb. meu irmão [divino é] alvorada, $1 \mathrm{Cr} 7,10$ ); 'ăhiyyâa/'ahyōw (heb. meu irmão [divino é] yhwh, 1Cr 8,7. 14. 31); 'ăḥ̂nō 'am (heb. meu irmão [divino é] agradável, 1Sm 14,50). (2) 'āb: 'ăbîhûd (heb. meu pai [é] glória, $1 \mathrm{Cr} 8,3$ ); 'ăbîš̂ua' (heb. meu pai [é] ajuda, $1 \mathrm{Cr} 8,4$ );

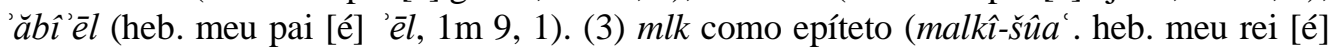
ajuda, 1Sm 14.49), predicado (melek, heb. rei, 1Cr 8, 35). (4) šahar: 'ăḥ̂šāhar (heb. meu irmão [divino é] šahar, 1Cr 7, 10), šẹharyâ (heb. šahar [é] yhwh, 1Cr 8, 26).

14 Ocorrências: (1) ba 'al: 'ešba 'al (heb. Baal existe / homem de Baal, 1Cr 8, 33, cf. 2Sm 2, 8); mĕpiba 'al (heb. Baal é amado, 1Cr 8,34). (2) 'èl: yĕdî' ‘̆ 'èl (heb. conhecedor de 'èl, 1Cr 7,6); 'elpā'al (heb. 'ēl tem feito, $1 \mathrm{Cr} 8,11$ ); mîkā'èl (heb. quem [é] como 'êl?,1Cr 8, 16); 'ělî'èl (heb. meu 'ēl [é] 'èl, 1Cr 8, 20). (3) mwt: yěrēmōwt (heb. mwt [é] exaltado, $1 \mathrm{Cr} 7,7.8$; 8, 14). (4) 'nt: 'ănātōwt (heb. Anate é grande, $1 \mathrm{Cr} 7,8$ ); 'antōtiyyâ (heb. Anate [é] yhwh, $1 \mathrm{Cr}$ 8, 24). (5) šmš: šamšěray (heb. šemeš guarda, $1 \mathrm{Cr} 8,26)$.

15 As ocorrências riscadas na linha final da tabela ("total") representam aquelas que não encontram correspondência entre os dois corpos de fontes incorrendo, portanto, em menor probabilidade histórica.

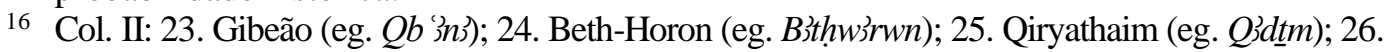
Aijalon (eg. 'Iywrwn). col. V: 57. Zemaraim (eg. D's[m]rwms); 58. Migdol (eg. [Mg]drw) (RITNER, 2009). 
Horon (Coluna II, n. 24; veja Js 18, 13-14). O deus canaaneu Horon era, também, uma divindade ctônica invocada em maldições em Ugarit e cultuada em diferentes formas no Egito (RÜTERSWÖRDEN, 1999), podendo aparecer como falcão, como é o caso de uma estátua de Ramsés II em Tânis ${ }^{17}$.

\section{Um panteão benjaminita?}

Os dados minerados da pesquisa da cultura visual e os nomes da cultura textual podem parecer caóticas à primeira vista. Contudo, uma vez que se pressuponha que diferentes mídias como a verbal e a visual ocultam diferentes concepções de uma mesma sociedade, é possível organizar o quebra-cabeça. Mesmo notando a falta de nomes nas fontes primárias (i.e., neste caso, fontes iconográficas), os diferentes perfis desempenhados pelas divindades parecem evidentes. Apesar do termo panteão poder ser um grande salto, haja vista as evidências não surgirem sistematicamente em todos os sítios do período, penso ser possível pressupor que as sociedades projetavam concepções sociais nas esferas divinas, produzindo quadros sociomórficos ${ }^{18}$ da interação entre divindades. A organização da sociedade benjaminita como uma chefatura complexa, na qual os líderes eram provavelmente divinizados (KLEIN CARDOSO, 2021), parece representar um conceito organizador suficientemente seguro.

Da pressuposição podemos sugerir três estratos de divindades. No primeiro estrato, as principais figuras da sociedade eram provavelmente representadas na forma de um casal divino. Isso pode ser sugerido tanto pelo caráter clânico da sociedade, quanto pelo fato do poder ser atribuído hereditariamente. Assim, o casal divino era provavelmente composto pela deusa-mãe, que assegurava sustento, colheitas (Fig. 1ac) e a fertilidade de animais (Fig. 1 d, e, i-o) e seres humanos (Fig. 1g-h). Não é possível nomear tal figura divina da evidência textual mas, talvez, seja possível sugerir o nome Aserá. A figura paterna, por sua vez, apresenta o perfil de deus do clima e cumpriria o papel de líder do clã sobre o trono (Fig. 2c), assegurando nutrição e o bom tempo para colheita e aumento dos rebanhos (Fig. 2a-b). O registro textual também não é claro aqui e tal deidade poderia ser cultuada pelo nome El ou Baal. Nesse sentido, é possível considerar a evidência tardia do nome dos filhos de Saul como vestígios de uma damnatio memoriae. Esse é, p. ex., o caso da famosa alteração no nome de 'ešba 'al $(1 \mathrm{Cr} 8,33)$ para 'î̌s bōšet $(2 \mathrm{Sm} \mathrm{2,8).} \mathrm{Partindo} \mathrm{desses} \mathrm{pressupostos,} \mathrm{Baal} \mathrm{é} \mathrm{a} \mathrm{melhor} \mathrm{hipótese,}$ mesmo que surja em um perfil iconográfico híbrido, i.e., em uma posição geralmente atribuída a El (Fig. 2c).

O segundo nível sociomórfico seria representado pela prole dessas deidades, que cumpririam um papel secundário no panteão. A deusa da guerra e caça seria a principal figura nesse contexto (Fig. 3a-c) e estaria ao lado de um deus ctônico da guerra e praga (Fig. 4a-b). A partir do registro textual, é possível sugerir que o nome da deusa da

17 Há, de fato, um amuleto de falcão em Nasḅeh (HERRMANN, 1994, p. 591) e um selo com o motivo em el-Jib (KEEL, 2013, p. 468, no. 6), mas por razões iconológicas, não é possível associá-los a Hórus.

18 Assim como o termo antropomórfico remete à forma (gr. morphē) de seres humanos (gr. anthrōpos) e o termo teriomórfico remete à forma (gr. morphē) de animais selvagens (gr. thērion), o termo sociomórfico é utilizado para remeter a fenômenos, objetos ou seres que possuem ou espelham a forma da sociedade (lat. socius). 
guerra nesse contexto fosse Anate. Embora seja possível conectar o perfil iconográfico do deus ctônico com Mot, a representação iconográfica deste último é incerta. A divindade desértica funcionaria como um/a forasteiro/a responsável por lutar contra forças caóticas, aparecendo em sua figuração heroica (Fig. 5c) e benevolente (Fig. 5b). É difícil nomear essa divindade, mas a sugestão de que seja $y h w h$, dado o contexto bíblico, não deve ser descartada (p. ex., 1Sm 13, 16; 1Cr 8, 35-37).

\section{Perspectivas}

O artigo discutiu os seres não-óbvios ou sobrenaturais que seriam supostamente objeto de devoção no platô de Benjamim no Período do Ferro I-IIA. A tarefa de identificar deidades em uma pequena parte da região montanhosa central no final do Ferro I foi descrita no passado como impossível, haja vista o retrato bíblico ser tardio e apresentar distorções (FINKELSTEIN, 2015, p. 71, n. 6). Frente ao desafio, propus um quadro teórico-conceitual que considera as estruturas comunicativo-religiosas da região, o qual tenho chamado nos últimos anos de "redes mágico-míticas". Desse ponto de partida, a pesquisa investigou as constelações iconográficas e a onomástica pertinente, sugerindo a organização sociomórfica de divindades.

Devo ressaltar que os dados apresentados não são capazes de apresentar uma reconstrução abrangente das crenças e práticas religiosas do platô de Benjamim no Ferro I-IIA. Em primeiro lugar, as fontes não são capazes de retratar todos os estratos sociais, haja vista a maior parte dos dados advir de uma aristocracia rural. De igual modo, deve-se ter em mente os diferentes usos de artefatos, uma questão que não pôde ser respondida aqui. Em segundo lugar, a escolha por uma análise estatística deixa outras figurações que foram consideradas menos representativas como, p. ex., amuletos de Bes e Hórus (HERRMANN, 1994, p. 365, 591, nos. 416, 861). Contudo, o tipo de dados acessados pode proporcionar um vislumbre da imaginação cultural dos líderes ou membros proeminentes dessa sociedade.

Desse pano de fundo, dois níveis de divindades são sugeridos. No primeiro, surge um casal divino com uma deusa-mãe, e um deus do clima entronizado, Baal. O segundo nível seria construído por divindades com papéis funcionais, nos quais é possível identificar a presença de uma deusa da guerra e de um deus guerreiro ctônico que, provavelmente, atendiam pelos nomes Anate e, talvez, Mot. Enquanto o aspecto reprodutivo estava ao encargo dos chefes do panteão, outros componentes sustentavam simbolicamente a sobrevivência da chefatura. Nesse aspecto, a divindade forasteira, que advinha do deserto, estava encarregada das forças do caos e pode ter atendido pelo nome de yhwh.

\section{Referências}

ALBERTZ, Rainer; SCHMITT, Rüdiger. Family and Household Religion in Ancient Israel and the Levant. Winona Lake: Eisenbrauns, 2012.

BARROS, José D’Assunção de. Fontes históricas: introdução aos seus usos historiográficos. Petrópolis: Vozes, 2019. 
BLENKINSOPP, Joseph. Gibeon and Israel: the role of Gibeon and Gibeonites in the political and Religious History of Early Israel. Cambridge: Cambridge University Press, 1972.

BOURDIEU, Pierre. Esboço de uma teoria da prática: precedido de três estudos de etnologia cabila. Oeiras: Celta Editora, 2002.

CALLAWAY, Joseph A.; COOLEY, Robert E. A Salvage Excavation at Raddana, in Bireh. Bulletin of the American Schools of Oriental Research, Jerusalem, n. 201, p. 9-19, feb. 1971.

CORNELIUS, Izak. The Iconography of the Canaanite Gods Reshef and Ba'al: Late Bronze and Iron Age I Periods (c 1500-1000 BCE). Fribourg, Suíça: University Press; Göttingen: Vandenhoeck \& Ruprecht, 1994.

CORNELIUS, Izak. The Many Faces of the Goddess: The Iconography of the Syro-Palestinian Goddesses Anat, Astarte, Qedeshet, and Asherah c. 1500-1000 BCE. Fribourg, Suíça: University Press; Göttingen: Vandenhoeck \& Ruprecht, 2008.

DAVIES, Philip R. In Search of Ancient Israel: a study in Biblical origins. London: T\&T Clark, 2015.

DIETRICH, Walter. The Early Monarchy in Israel: the tenth century BCE. Atlanta: SBL, 2007.

EHRLICH, Carl S. (Ed.). Saul in Story and Tradition. Tübingen: Mohr Siebeck, 2006.

ELITZUR, Yoel. Ancient place names in the Holy Land: preservation and history. State Park: Eisenbrauns, 2004.

FAUST, Avi. Settlement Patterns and State Formation in Southern Samaria. In: EHRLICH, Carl S. (Ed.). Saul in Story and Tradition. Tübingen: Mohr Siebeck, 2006. p. 14-38.

FINKELSTEIN, Israel. First Israel, Core Israel, United (Northern) Israel. Near Eastern Archaeology, Chicago, v. 82, n. 1, p. 8-15, 2019.

FINKELSTEIN, Israel. O Reino Esquecido: arqueologia e história de Israel Norte. São Paulo: Paulus, 2015.

FINKELSTEIN, Israel; MAGEN, Yitzhak (Eds.). Archaeological Survey of the Hill Country of Benjamin. Jerusalem: IAA, 1993.

FINKELSTEIN, Israel; RÖMER, Thomas. Kiriath-jeraim, Kiriath-baal/Baalah, Gibeah: A Geographical-History Challenge. In: KOCH, Ido; RÖMER, Thomas; SERGI, Omer (Eds.). Writing, Rewriting, and Overwriting in the Books of Deuteronomy and the Former Prophets: essays in honour of Cynthia Edenburg. Leuven; Paris; Bristol: Peeters, 2019. p. 211-222.

FLEMING, Daniel. The Legacy of Israel in Judah's Bible: history, politics, and the reinscribing of tradition. New York: Cambridge University Press, 2012.

FLUSSER, Vilém. Comunicologia: reflexões sobre futuro. São Paulo: Martins Fontes, 2014.

GIFFONE, Benjamin D. 'Sit at my Right Hand': the Chronicler's portrait of the Tribe of Benjamin in the social context of Yehud. London: T\&T Clark, 2018.

GOLUB, Mitka. The Distribution of Personal Names in the Land of Israel and Transjordan during the Iron II Period. Journal of American Oriental Society, Ann Arbor, v. 134, n. 4, p. 621-642, 2014. 
HERRMANN, Christian. Ägyptische Amulette aus Palästina / Israel: Mit einem Ausblick auf ihre Rezeption durch das Alte Testament. Fribourg, Suíça: University Press; Göttingen: Vandenhoeck \& Ruprecht, 1994.

KEEL, Othmar. Bildträger aus Palästina/Israel und die besondere Bedeutung der Miniaturkunst. In: KEEL, Othmar; SCHROER, Silvia (Eds.). Studien zu den Stempelsiegeln aus Palästina/Israel Bd I. Fribourg, Suíça: University Press; Göttingen: Vandenhoeck \& Ruprecht, 2008, 1985, p. 7-47.

KEEL, Othmar. Corpus der Stempelsiegel-Amulette aus Palästina/Israel: Von den Anfängen bis zur Persezeit. Fribourg, Suíça: University Press; Göttingen: Vandenhoeck \& Ruprecht, 2008, 1995, 1997, 2010a, 2010b, 2013, 2017. 6 v.

KEEL, Othmar; UEHLINGER, Christoph. Gods, Goddesses and Images of God in Ancient Israel. Minneapolis: Fortress Press, 1998.

KEEL, Othmar. Jahwes Entgenung an Ijob: Eine neue Deutung von Ijob 38-48 vor dem Hintergrund der zeitgenössischen Bildkunst. Göttingen: Vandenhoeck \& Ruprecht, 1978.

KLEIN CARDOSO, Silas. Amuletos como mídia: poder estampado em ossos e o "Antigo Israel". Caminhando, São Bernardo do Campo, v. 25, n. 1, p. 141-161, 2020a.

KLEIN CARDOSO, Silas. Redes mágico-míticas no alvorecer de Israel: "religião" no platô de Benjamim no Ferro I-IIA. 2019. Tese (Doutorado em Ciências da Religião) - Universidade Metodista de São Paulo, São Bernardo do Campo, 2019.

KLEIN CARDOSO, Silas. Sotaques do poder: recombinações visuais e os fundamentos do imaginário régio judaíta. Caminhando, São Bernardo do Campo, v. 26, p. 1-21, 2021.

KLEIN CARDOSO, Silas. Templos da Casa de Saul? Dissonâncias entre o registro bíblico e material. Caminhando, São Bernardo do Campo, v. 25, n. 2, p. 55-76, 2020 b.

KNAUF, Ernst A. Qôs. In: TOORN, Karel van der; BECKING, Bob; HORST, Pieter W. van der (Orgs.). Dictionary of deities and demons in the Bible. Leiden: Brill, 1999a. p. 674-677.

KNAUF, Ernst A. Shadday. In: TOORN, Karel van der; BECKING, Bob; HORST, Pieter W. van der (Orgs.). Dictionary of deities and demons in the Bible. Leiden: Brill, 1999b. p. 749-753.

KNAUF, Ernst A. The impact of the Late Bronze III Period on the origins of Israel. In: GRABBE, Lester L. (Ed.). The Land of Canaan in the Late Bronze Age. London: Bloomsbury T\&T Clark, 2016. p. 125-132.

KNAUF, Ernst A.; GUILLAUME, Philippe. A History of Biblical Israel: the fate of the tribes and kingdoms from Merenptah to Bar Kochba. Sheffield: Equinox, 2016.

KNOBLAUCH, Hubert. The communicative construction of reality. London: Routledge, 2020.

KOCH, Ido. Late Iron Age I Southwestern Canaanite Multi-Facet Stamp-Amulets: Innovative Imagery and Interpreted Egyptian Heritage. In: SHAI, Itzhaq; CHADWICK, Jeffrey R.; HITCHCOCK, Louise; DAGAN, Amit; McKINNY, Chris; UZIEL, Joe (Eds). Tell it in Gath, studies in the History and Archaeology of Israel: essays in honor of Aren M. Maeir on the occasion of his $60^{\text {th }}$ Birthday. Münster: Zaphon, 2018. p. 632-652.

KRAUSE, Joachim J.; SERGI, Omer; WEINGART, Kristin. Saul, Benjamin, and the emergence of monarchy in Israel: Biblical and Archaeological perspectives. Atlanta: SBL Press, 2020.

LANGE, Armin. Ancient and Late Ancient Manuscript Evidence. In: LANGE, Armin; TOV, Emanuel (Ed.). Textual History of the Bible 1B. Leiden: Brill, 2016. E-book. 
LANGSTON, Scott M. Cultic Sites in the Tribe of Benjamin: Benjaminite prominence in the religion of Israel. New York: Peter Lang, 1998.

LEDERMAN, Zvi. An Early Iron Age village at Khirbet Raddana: the excavations of Joseph A. Callaway. 1999. Tese (Doutorado em Near Eastern Languages and Civilizations) - Harvard University, Cambridge, 1999.

LEHMANN, Gunnar. Clan. In: ALLISON, Dale C. et al. (Eds.). Encyclopedia of the Bible and its Reception. Berlin: De Gruyter, 2012. p. 381-385.

LEHMANN, Gunnar. Reconstructing the social landscape of Early Israel: rural marriage alliances in the Central Hill Country. Tel Aviv, Tel Aviv, v. 31, n. 2, p. 141-193, 2004.

LEHMANN, Gunnar; VARONER, Oz. Early Iron Age tombs in Northern Israel revisited. Tel Aviv, Tel Aviv, v. 45, n. 2, p. 235-272, 2018.

MANDEL, Alice; SMOAK, Jeremy. The material turn in the study of Israelite religions: Spaces, Things, and the Body. Journal of Hebrew Scriptures, Edmonton v. 19, p. 1-42, 2019.

MARQUET-KRAUSE, Judith. Les fouilles de 'Ay (Et-Tell), 1933-1935: la résurrection d'une grande cité biblique. Paris: Geuthner, 1949.

McCOWN, C. C. Tell en-Nasbeh I: Archaeological and Historical results. Berkeley: The Palestine Institute of Pacific School of Religion; AASOR, 1947.

MEYER, Birgit. Religion as mediation. Entangled Religions, Bochum, v. 11, n. 3, p. 1-21, 2020.

MILLER II, Robert D. Chieftains of the highland clans: History of Israel in twelfth and eleventh centuries B.C. Grand Rapids: Eerdmans, 2005.

MILSTEIN, Sara J. Tracking the Master Scribe: revision through introduction in Biblical and Mesopotamian literature. New York: Oxford University Press, 2016.

MÜNGER, Stefan. Stamp-seal Amulets and Early Iron Age Chronology: an update. In: LEVY, Thomas E.; HIGHAM, Thomas (Eds.). The Bible and radiocarbon dating: Archaeology, text and science. London: Routledge, 2005. p. 381-404.

MÜNNICH, Maciej M. The God Resheph in Ancient Near East. Tübingen: Mohr Siebeck, 2013.

NOTH, Martin. Die israelitischen Personennamen im Rahmen der gemeinsemitischen Namengebung. Sttutgart: Kolhhammer, 1928.

ORNAN, Tallay. The bull and its two masters: moon and storm deities in relation to the bull in Ancient Near Eastern Art. Israel Exploration Journal, Jerusalem, v. 51, n. 1, p. 1-26, 2001.

RAINEY, Anson F. The Toponymics of Eretz-Israel. Bulletin of the American Schools of Oriental Research, Jerusalem, v. 231, p. 1-17, out. 1978.

RITNER, Robert K. The bubastite Portal Karnak: Relief Sheshonq I. In: RITNER, Robert K (Org.). The Lybian Anarchy: Inscriptions from Egypt's Third Intermediate Period. Atlanta: SBL, 2009. p. 193-210.

ROUBEKAS, Nickolas P. (Ed.). Theorizing "religion” in antiquity. Sheffield: Equinox, 2019.

RÜTERSWÖRDEN, Udo. Horon. In: TOORN, Karel van der; BECKING, Bob; HORST, Pieter W. van der (Orgs.). Dictionary of deities and demons in the Bible. Leiden: Brill, 1999. p. 425-426. 
SASS, Benjamin; FINKELSTEIN, I. The Swan-Song of Proto-Canaanite in the ninth century BCE in light of an alphabetic inscription from Megiddo. Semitica et Classica, Turnhout, v. 9, p. 19-42, 2016.

SCHACHTER, Batyah. Dance in Iron Age Israel/Palestine 1200 - 600 B.C.: Archaeological sources and Glyptic Art. In: DUMBRILL, Richard J. (Ed.). Proceedings of the International Conference of Near Eastern Archaeomusicology, ICONEA 2009-2010. London: ICONEA; Gorgias Press, 2010. p. 143-159.

SCHROER, Silvia. Die Ikonographie Palästinas/Israels und der Alte Orient: Eine Religionsgeschichte in Bildern. Fribourg: Schwabe; Bibel+Orient Museum, 2005, 2008a, 2011, 2018. 4 v.

SCHROER, Silvia. Vulture. In: EGGLER, Jùrg; UEHLINGER, Christoph. (Eds.). Iconography of Deities and Demons in the Ancient Near East. Zürich: Swiss National Science Foundation, 2008b.

SERGI, Omer. The Emergence of Judah as a Political Entity between Jerusalem and Benjamin. Zeitschrift des Deutschen Palästina-Vereins, Tübingen, v. 133, n. 1, p. 1-23, 2017.

SHUVAL, Menakhem. A Catalogue of Early Iron Stamp Seals from Israel. In: KEEL, Othmar; SHUVAL, Menakhem; TIGAY, Jeffrey H. (Orgs.). You shall have no other gods: Israelite religion in the light of Hebrew inscriptions. Atlanta: Scholars Press, 1986.

STAUBLI, Thomas. Bull leaping and other images and rites of the Southern Levant in the sign of Scorpius. Ugarit-Forschungen, Münster, v. 41, p. 611-630, 2010.

TOORN, Karel van der. Family Religion in Babylonia, Syria and Israel: continuity and change in the forms of religious life. Atlanta: SBL Press, 1996.

UEHLINGER, Christoph (Ed.). Studien zu den Stempelsiegeln aus Palästina/Israel Bd III: Die Frühe Eisenzeit, Ein Workshop. Fribourg, Suíça: University Press; Göttingen: Vandenhoeck \& Ruprecht, 1990.

UEHLINGER, Christoph. Bildquellen und 'Geschichte Israels' Grundsätzliche Überlegungen und Fallbeispiele. In: HARDMEIER, Christof (Ed.). Steine-Bilder-Text: Historische Evidenz außerbiblischer und biblischer Quellen. Leipzig: Evangelische Verlagsanstalt, 2001. p. 25-77.

ZADOK, Ran. The pre-Hellenistic Israelite anthroponymy and prosopography. Leuven: Peeters, 1988.

ZEVIT, Ziony. The Religions of Ancient Israel: a synthesis of parallactic approaches. New York: Continuum, 2001. 